\title{
LITERATURA NEGRO-BRASILEIRA DO ENCANTAMENTO INFANTIL E JUVENIL: ENTREVISTA COM KIUSAM DE OLIVEIRA
}

\section{BLACK-BRAZILIAN LITERATURE OF CHILD AND JUVENILLE'S EN- CHANTMENT: INTERVIEW WITH KIUSAM DE OLIVEIRA}

Oluwa Seyi Salles Bento ${ }^{1}$

\begin{abstract}
Resumo: Entrevista com a escritora, bailarina, educadora e contadora de histórias Kiusam de Oliveira, realizada em 26 de maio de 2020, via e-mail.
\end{abstract}

Abstract: Interview with writer, ballerina, educator and storyteller Kiusam de Oliveira, conducted in May 26th 2020 , by e-mail.

Palavras-chave: Literatura para crianças e jovens; Literatura negro-brasileira; educação; antirracismo.

Keywords: Literature for children and young; Black-Brazilian literature; education; anti-racism.

Kiusam de Oliveira é escritora, dançarina, educadora, contadora de histórias, militante antirracista e sacerdotisa de candomblé. Nascida em Santo André, região Metropolitana de São Paulo, atualmente reside no Espírito Santo, onde é docente da Universidade Federal (UFES). Cursou Magistério no Colégio IESA e Pedagogia na Fundação Santo André. Especializou-se e realizou mestrado e doutorado nas área da Educação e Psicologia, na Universidade de São Paulo (USP).

É autora dos livros Omo-obá: histórias de princesas (ilustrações de Josias Marinho, Mazza Edições, 2009), que recebeu o selo "Altamente Recomendável” da Fundação Nacional do Livro Infantil e Juvenil (FNLIJ), em 2010, e foi selecionado pelo Programa Nacional Biblioteca na Escola (PNBE), em 2011; O mundo no Black power de Tayó (ilustrações de Taisa Borges, Editora Peirópolis, 2013), agraciado com o Prêmio PROAC de Cultura Negra, em 2012, incluído no ranking da ONU dos 10 livros mais importantes do mundo em Direitos Humanos e selecionado para o Acervo básico da FNLIJ, na categoria Criança, em 2014; O mar que banha a ilha de Goré (ilustrações de Taisa Borges, Editora Peirópolis, 2015), ganhador do Prêmio Escritores Negros da Biblioteca Nacional e da Secre-

1 Mestranda do Programa de Pós-graduação em Estudos Comparados de Literaturas de Língua Portuguesa da Universidade de São Paulo (USP). Bolsista CAPES. 
taria Nacional de Políticas de Promoção da Igualdade Racial (SEPPIR), em 2014; e O Black power de Akin (ilustrações de Rodrigo Andrade, Editora da Cultura, 2020).

Revista Crioula: Suas primeiras opções profissionais, ainda na infância, já eram relacionadas à educação, à escrita e à dança?

Kiusam de Oliveira: Minhas primeiras opções profissionais, ainda na infância, sempre foram voltadas para a educação, escrita e dança. Isto se deu pelo fato de ter ido à Escolinha da Dona Marta, aos dois anos e seis meses de idade e lá ter encontrado um mundo encantado voltado para as Artes. Assim que ingressei na escola, interpretei, no teatro, o papel de um ovo e o carreguei pendurado no pescoço, feito com cartolina, dois furos nas extremidades e um barbante. Lá, aprendi a amar o teatro, a dança e as passarelas.

Aos quatro anos, aprendi a ler e a escrever, ensinada que fui pela minha mãe; e desde sempre escrevo histórias em bloquinhos de notas, aqueles que minha mãe colocava em minhas capangas de tricô e/ou crochê que ela mesmo fazia. Aos cinco para seis anos, minha mãe me matriculou em uma escola de ballet: amei o jazz, mas por ser muito nova, minha única opção foi cursar o clássico. Aos 12 anos, eu tive a minha primeira turma de 'baby class', dando aulas de ballet clássico para bebês.

Paralelo a tudo isso, sofria imensamente com o racismo vindo dos profissionais da educação que me deseducavam, ensinando-me a odiar meu corpo negro. Eu já os desafiava afirmando que seria professora só para esfregar em suas caras que eu seria bem melhor que eles e elas no trato com o ser humano. Assim, tratei de trilhar esse caminho.

Em algum momento, me encantei pela medicina, mas minha mãe sepultou esse sonho quando disse que a única opção que eu tinha era cursar um segundo grau profissionalizante para que tivesse condições de arcar com as minhas despesas e ajudar em casa. Retomei meu sonho original e, assim, segui. A vida inteira, desde meus 12 anos, divido meu tempo de trabalho com o magistério, com a dança e com a escrita.

Revista Crioula: Lemos na introdução de sua tese e na entrevista cedida ao Portal Geledés que você sofreu discriminação racial de uma professora durante a infância. Esse fato foi preponderante na sua escolha pela literatura? De que maneira? 
Kiusam de Oliveira: Aos cinco para seis anos, precisei sair da Escolinha da Dona Marta por conta da idade e minha mãe viu-se em situação complicada. Como eu amava estudar, ela achou por bem que eu desse sequência e isso só foi possível em uma escola particular. Era uma escola confessional, de freiras, próxima de casa. Lá conheci o racismo de várias formas. A forma mais contundente foi quando, por medo da madre superiora, que naquela manhã substituiu a minha professora, fiz xixi no meio da sala de aula, quando ela negou meu pedido para ir ao banheiro. Ela grudou em minha orelha e foi me arrastando escadaria abaixo. No banheiro, tirou toda a minha roupa e jogou meu corpo embaixo do chuveiro de água fria de junho. Enquanto eu berrava, achando que a minha mãe ouviria meu choro lá de casa, ela colocou dentro de minha boca um tufo de papel higiênico, da marca Primavera, da década de 1970: totalmente áspero; este cortou a minha gengiva e, junto com a água, o sangue tingia o piso branco. Antes de sair do banheiro, a madre gritou "não saia daí", para mim. Ao retornar, trouxe todos os meus colegas de sala que, euforicamente, gritavam "a macaca pelada, a macaca pelada". Foi quando a madre gritou com eles, dizendo "Calados! Olhem bem para o que estão vendo: é assim que todo o preto deve ser tratado".

Era 1971. Esse fato destruiu a minha autoestima e qualquer possibilidade de reconstruí-la somente com o apoio de meus pais. Daí até meus doze anos, fui ladeira abaixo. No ballet, quis alisar meus cabelos, pois apesar de saber que era incrível já aos 10 anos, minha professora afirmou que eu jamais seria a primeira bailarina porque eu era preta e tinha o cabelo duro. E aos 12 anos, o professor André, de Geografia, afirmou que eu nem precisava fazer a lição de casa, uma vez que não passaria de uma empregada doméstica e me convidou para cuidar dos gêmeos que sua esposa ia parir. Esses fatos foram decisivos para o ódio que desenvolvi por mim mesma. Então, minha mãe intensificou a busca por ajuda. Até aí, minha escrita era totalmente de ódio ao branco e totalmente focada na temática das relações étnico-raciais.

Revista Crioula: Em 2009, você já era professora, bailarina, coreógrafa... Por quê e como surgiu a literatura enquanto outro ofício?

Kiusam de Oliveira: Em 2009, lancei meu primeiro e premiado livro - Omo-Oba: Histórias de Princesas, da Mazza Edições -, mas a corrida pela publicação começou quatro anos antes, em vão. Isso se deu para atender às necessidades de estudantes negros que, desde 1981, quando eu fui para sala de aula como estudante do curso Magistérios de $2^{\circ}$ Grau, afirmavam a não existência de princesas negras, quando eu sabia de sua existência.

Uma noite, em 2004, sonhei com minhas ancestrais Oxum e Iansã e ambas anunciavam para mim uma missão que eu deveria cumprir atentando para todas as orientações que elas me davam. Não 
cumpri uma delas, por arrogância, entendo. Apesar de terem me orientado a não colocar a palavra orixá nos textos, eu coloquei, achando ser um marcador fundamental para resistência em um país racista. E assim, rodei por quase quatro anos nessa luta para conseguir uma editora para publicar meus textos.

Após esse tempo, corri para dois babalorixás e uma iyalorixá, meus mais velhos, para que me dissessem o que estava acontecendo, uma vez que estava cumprindo a missão que havia sido dada. Eles e ela foram unânimes em pedir para eu olhar novamente para os textos, pois algo não estava de acordo com o determinado. Somente no terceiro jogo divinatório que, como num despertar, me lembrei da frase dita por elas, juntas, quando determinaram para não usar a palavra orixá. Então, limpei o texto e enviei novamente para três editoras, as quais eu já havia enviado e me retornaram, com carta, rejeitando meus textos. A Editora Mazza, imediatamente, me enviou e-mail perguntando "de onde veio esse trecho de texto, tem mais?” e, assim, o livro está aí há 10 anos.

Eu reconheço que escrevo para dar uma resposta à minha criança interior. Eu era muito indefesa e apesar da minha mãe ter sido uma combatente na luta antirracista, eu não conseguia colocar meu corpo para o enfrentamento das violências racistas que meus professores e colegas de classe jogavam sobre mim. Eu tenho vários ofícios, não gosto de me prender a um: sou múltipla. Entendo, como Stuart Hall, que tenho múltiplas identidades e, em cada momento, necessito da expertise de uma delas, ligadas que estão aos diversos campos de trabalho, de minha formação. Minha mãe, na década de 1970, já dizia que nós tínhamos múltiplas inteligências, e ela, com o pouco estudo que tinha, jamais

soube quem foi o psicólogo Howard Gardner e seu conceito de Inteligências Múltiplas (1980), que pontua as inteligências musical, linguística, lógico-matemática, interpersonal/intrapersonal, naturalista, corporal/cinestésica e espacial. Entendo que, destas, a que menos desenvolvi, foi a lógico-matemática, apesar da minha mãe ser incrível nesta área. A literatura é, portanto, uma das muitas áreas com as quais trabalho e me empenho. É a que está em destaque pela imprensa e demais profissionais nesse momento.

Revista Crioula: Durante sua infância e formação básica, como você percebia e recebia a literatura para crianças e jovens?

Kiusam de Oliveira: A literatura para as infâncias era ínfima. Monteiro Lobato era a base de tudo, o que me causava enorme desconforto, já que não nutria a menor simpatia pelos seus escritos por conta da forma violenta com que se referia aos negros e negras. Doía meu coração e, por isso, eu retardava todas as leituras dos livros dele. Por vezes, minha mãe lia para mim, enquanto eu chorava com toda aquela violência, mas eu precisava dar conta de entender tudo para tirar notas boas em sala de aula. Minha mãe não admitia menos que nota nove e eu a ouvia constantemente dizendo que eu deveria ser 
1000 vezes melhor que qualquer branco. Assim o era. Assim o é.

Aos nove anos, minha mãe fez uma assinatura de um clube de livros chamado Círculo do Livro e, então, pude escolher para a compra meus primeiros livros, que foram: Os Lusíadas, de Luís de Camões, Os Sertões, de Euclides da Cunha e A Insustentável Leveza do Ser, de Milan Kundera. Após esses, adquiri $O$ Cortiço, de Aluísio de Azevedo, Capitães da Areia, de Jorge Amado e Negras Raízes, de Alex Haley. Depois, escolhi as biografias de Winnie Mandela, Martin Luther King, Malcolm X (com o qual imediatamente me identifiquei, por conta do ódio que eu já nutria pelos brancos), Desmond Mpilo Tutu, que recebeu o Prêmio Nobel em 1984 e tive a honra, em 2001, aqui no Brasil, de sentar junto, conversar e abraçar. Minha leitura se deu através de livros para adultos e com a ajuda do dicionário. Era comum eu caminhar de casa para a escola com os dois nas mãos, pois achava chique demais. Os livros sempre foram valores para a minha família: éramos muito pobres e tudo era feito com sacrifícios imensos do meu pai e da minha mãe.

Revista Crioula: E, mais recentemente, quais são as mudanças que você pontuaria como as mais importantes nesse cenário, sobretudo pela perspectiva racial?

Kiusam de Oliveira: Hoje, apesar de termos políticas públicas focadas no incentivo à leitura e literatura, ainda vivemos num país em que se dá pouco valor aos livros e à revolução que uma boa leitura é capaz de provocar. Literatura como ferramenta para fortalecer identidades, para combater as diversas discriminações, como alimento estratégico para o corpo e alma. São políticas que efetivamente estão no papel, sem que, de fato, investimentos sejam feitos nessa área. As grandes ações se dão através de grupos privados, ONGs e Institutos. Nas periferias, a literatura negro-brasileira tem revolucionado as vidas de seus habitantes. É revolucionário o trabalho que as bibliotecas comunitárias têm feito nas periferias do país e com mediadores de leituras voluntários. Na perspectiva de mudanças no território literário com foco na temática racial, as mudanças dizem respeito à ampliação da consciência de que uma literatura negro-brasileira é capaz de fortalecer identidades de crianças, jovens e adultos negros, aumentar a autoestima e trazer à luz estratégias possíveis de serem aplicadas no cotidiano.

Revista Crioula: De que modo você percebe a recepção da literatura pelas crianças e pelos jovens hoje?

Kiusam de Oliveira: Crianças gostam de livros, de literatura. O que ocorre é que são desestimuladas a recorrerem aos livros, ao longo das vidas pessoal e escolar. A pobreza das famílias faz com que todos se afastem dos livros, um bem ainda muito caro e com isso, a falta de hábito na leitura, também faz parte da perpetuação desse quadro. Mas não se trata, apenas, de preço: as bibliotecas públicas, 
muitas vezes estão nos bairros e passam por ameaças constante de fechamento. Nas escolas, os livros sempre estão em lugares inacessíveis às infâncias, em altas estantes, muito porque os profissionais da educação sabem o quão difícil se faz uma compra de livros, tendendo a deixá-los, de fato, longe das crianças, para sua conservação. Tudo isso, coloca os livros e a leitura bem longe dos corpos infantis, juvenis, de seus cotidianos. Enquanto na Educação Infantil o momento da mediação de leitura faz parte do cotidiano de sala de aula, no Ensino Fundamental I e II, os livros se afastam das crianças e jovens: as leituras diárias deixam de existir e passam a ser estimuladas mensal ou bimestralmente. No Ensino Médio, os livros e leituras ficam mais distantes ainda dos jovens, sendo estimuladas como preparação para vestibular, aí, já com uma função mais pesada que simplesmente ler por prazer.

Revista Crioula: Como você percebe a recepção das crianças e jovens para as narrativas que apresentam contranarrativas acerca de raça e de religião?

Kiusam de Oliveira: As contranarrativas que tenho apresentado em meus textos, no formato de livros, são recebidas com festejos por profissionais da educação, pais e mães, tios e tias, padrinhos e madrinhas, irmãos e irmãs. São narrativas altamente celebradas que, de fato, fortalecem a autoestima das crianças e jovens negros, por apresentarem personagens negros fortalecidos em suas identidades. As crianças negras e não-negras não questionam as passagens em que cito a ancestralidade africana, mas algumas crianças negras e não-negras se emocionam e comentam comigo pertencerem à umbanda ou ao candomblé. Nesse momento, uma emoção enorme toma conta de todos nós e trocamos bênçãos. Eu entendo que tenho criado um território epistêmico na literatura que se chama Literatura Negro-Brasileira do Encantamento Infantil e Juvenil que se faz no campo da decolonialidade, a partir de alguns obeliscos que são marcadores fundamentais para reconhecer tal literatura. Importante destacar que o conceito criado por Cuti (Literatura Negro-Brasileira) é aqui chave para entender que tipo de negro/a é capaz de produzir tal literatura e não basta ser negro e se identificar como tal para produzir esse tipo literário. Vale a pena compreender tal conceito e o que entendo por Encantamento.

Revista Crioula: Como foi lidar com a mitologia dos orixás na produção do seu primeiro livro (Omo-obá: histórias de princesas, 2009) e direcioná-la ao público infantil?

Kiusam Oliveira: Omo-Oba veio de uma missão dada pelas minhas ancestrais Oxum e Iansã e só segui o que me mandaram fazer. Importante lembrar que só demorou para dar certo, pois não havia cumprido uma das determinações. Assim que eu me lembrei dela, durante um jogo de búzios, é que os caminhos foram abertos para tal publicação. Oxum e Iansã determinaram que as histórias deveriam focar crianças e jovens e, para isso, as imagens e as histórias deveriam ser apresentadas de um jeitinho 
a atender esses públicos. O que percebo é que esse livro, assim como os outros, têm sentido para todas as idades, e isso é o que eu sempre acreditei. O universo mitológico africano tem sido a minha vida, então, para mim, tudo é muito natural e para quem vive nesse universo também. Só fortalece.

Revista Crioula: De alguma maneira, a ibeji (gêmea) Taiyo de Ana Maria Gonçalves inspirou a sua Tayó?

Kiusam de Oliveira: Li Ana Maria Gonçalves após o lançamento de $O$ mundo no black power de Tayó (Editora Peirópolis, 2013), portanto, a única referência que eu tinha de Tayó era através do Culto aos Ibejis, no candomblé de ketu, nação da qual faço parte. Amo todos os meus livros: o protagonismo e ousadia em lançar um livro com princesas africanas, o texto da Tayó que escrevi no momento mais triste da minha vida, mas gostaria aqui de destacar $O$ mar que banha a Ilha de Goré (Editora Peirópolis, 2015) e O black power de Akin (Editora de Cultura, 2020), meu recém-lançamento. São duas histórias de fôlego, pequenos romances que trazem a ancestralidade de forma ampliada e aprofundada: o primeiro revela o diálogo que uma menina brasileira de 10 anos estabelece com sua ancestral mais antiga, a Mãe Mar, e com as Baobás; e a segunda traz um avô maravilhoso que representa a ancestralidade na contemporaneidade e resgata a autoestima de seu neto que sofre com violências por parte dos colegas de classe, que atingem sua estética negra e seus cabelos crespos. O avô carrega saberes ancestrais fundamentais para que qualquer criança e jovem se reestruturem em suas dignidades. É isso que trago em minhas histórias.

Revista Crioula: Se você pudesse indicar apenas uma obra sua a alguém que nunca leu nada de sua autoria, qual seria? Por quê?

Kiusam de Oliveira: Cansam de me pedir isso: indicação de um dos meus livros para quem não conhece meu trabalho e, nesse caso, indico $O$ mundo no black power de Tayó, pois Tayó é encantadora, não tem quem não a ame. É um bom começo para qualquer leitor, independente da idade.

Revista Crioula: A escrita, a dança, a religião, a contação de histórias: como a carreira acadêmica afetou suas tantas outras atividades?

Kiusam Oliveira: Sou uma mulher preta. Sempre fui, sempre soube disso, sempre senti as delícias e os dissabores de saber-me preta. A mim, parece natural tudo o que faço ser afetado pela minha raça/ cor tendo em vista o país onde nasci e moro, diante do racismo estrutural e estruturante. O racismo me estruturou para a luta e me reconheço bem bélica: minha forma bélica de ser apresenta-se através 
das palavras escolhidas para comporem minhas histórias; os temas, gestos e movimentos para comporem minhas coreografias; as epistemes negras com as quais desenvolvo minhas aulas e metodologias próprias de trabalho, como a Pedagogia Eco-Ancestral (ou da Ancestralidade), que se faz através da Literatura Negro-Brasileira do Encantamento. É a minha consciência racial, do racismo estrutural e estruturante e da branquitude que acionam em mim a urgência em trazer cor, tempero e sabor, dendê, pimenta e manjericão para os processos educativos de todas as áreas que tenho contribuído nesse país.

Revista Crioula: E, no caminho reverso, como a Kiusam militante antirracista, escritora, sacerdotisa de candomblé e narradora de histórias contribui para a formação dos alunos?

Kiusam de Oliveira: Tenho contribuído desde meus 15 anos com uma pedagogia afrorreferenciada, a qual sempre chamei de Pedagogia da Ancestralidade, discutindo questões focadas nos Direitos Humanos e pautando uma relação horizontal com meus estudantes, focada no amor. Simples assim. Complexo assim.

Revista Crioula: Quais são seus próximos passos e projetos na literatura?

Kiusam de Oliveira: Na literatura, assinei um contrato lindo com a Companhia das Letras para lançar um conteúdo focado em Tayó e Direitos Humanos, ainda sem nome. Faria quatro lançamentos em 2020, mas, por conta da pandemia, só publiquei um livro até agora. Os demais, não sei. O que recebo de informação é que só serão publicados mais adiante, ainda este ano. São projetos incríveis focados na diversidade - dentro do que sempre estive envolvida -, com lançamentos previstos no exterior. Estou muito feliz. No momento, estou escrevendo um romance, um livro de auto-ajuda e uma obra paradidática, tudo ao mesmo tempo. Tomei gosto pelos poemas e algo lindo está chegando também, a partir de um poema incrível que escrevi chamado "Vou tirá-la do seu altar". 